\title{
On Some Grammatical Peculiarities of Indian English
}

\section{Kristine Harutyunyan \\ Rafayel Harutyunyan}

Yerevan State University

\section{Abstract}

English is a lingua franca that unites all the nations in the world. It is not only the language of universal communication but also a language to access the scientific world, international business and the world of entertainment as many of the world's top films, books and songs are published and produced in English. The English that people use for social interaction in India differs considerably from the English spoken in other regions of the world in terms of vocabulary, syntax and other aspects of language. Thus, the aim of the present article is to investigate Indian English as a distinctive variety of English and to show how Indians have customized English in various ways, and willingly or unwillingly, have better suited it to their needs. We also discuss some grammatical peculiarities of Indian English used or experienced in different settings.

Key words: Indian English, linguistic variety/variation, social interaction, customization of English, grammatical peculiarities.

\section{Introduction}

Indian English, like all other languages in the world has a rich and interesting history from its birth to the present day. English has been with India since the colonization by Great Britain in the $16^{\text {th }}$ century. Once independence was proclaimed and the English left the country, people intuitively stopped perceiving English as having an alien power and their attitude towards the language totally changed; however, the controversy about English has continued to this day. Kachru (1986:12) notes that "English now has national 
and international functions that are both distinct and complementary. English has thus acquired a new power base and a new elitism."

Nowadays English remains in the heart of the Indian society and is massively used in contemporary India: in Indian newspapers, radio and television, in computing, internet and telephony, in public use and attitudes. But the term Indian English (IE) leads to different theoretical arguments. First of all Indian English is considered by many scholars to be a dialect of British English and Hindi (the official language of India). A dialect or not, Indian English has different linguistic peculiarities, including certain grammatical ones, which are typical of only this unique variety of English.

\section{What is Indian English?}

On the point where Indian English comes from, the opinions of linguists differ greatly: some highlight its English origin, pointing to the fact that most of the vocabulary of Indian English is from English. Logically, the word stock should be the same to some extent, otherwise there would not be arguments about Indian English and other variations of English. It is important to mention that the Indian English lexicon has many common terms which are practically used by its speakers and can be comprehensible only for its users. Some appeared to be in use through the realization of old and new morphological features, others come from acronyms and abbreviations. Certain terms from Indian languages are used, and new usages for English words or expressions are created.

Other scholars agree that Indian English and British English are different from the point of view of the number and realization of their phonemes, their intonation and their rhythm. These differences are apparent for listeners when trying to identify a speaker as British or Indian.

Indian English is an umbrella term which is used to describe all the dialects of the English language that are spoken in the Republic of India. Like other variations of the English language, Indian English is the result of language contact, which means it is "a product of contact between English and Indian mother tongues" (Sumana 2010:3). In other words, it is this contact that 
contributed to the development of the present-day Indian English. Thus, the mixture of certain linguistic aspects and different social backgrounds resulted in Indian English - a distinct variety of the English language.

\section{Grammatical Features of Indian English}

Grammar plays an essential role in learning and understanding a language because languages are not just made of certain words that can be fit in one syntagma but they should also follow certain rules that dictate how these words can work together to make sense. Of course, it is preferably important to know grammar well to communicate through a language accurately but it is not compulsory to follow all the grammar rules perfectly all the time for an effective communication. When we use a language, we adopt it to our articulatory system in general and this can lead to various grammatical mistakes from spelling to semantic meaning of a sentence, i.e. a slight mispronunciation can change completely the speaker's intention. For example: the market sells fresh food and the market sells fresh foot. This kind of mispronunciation is more typical of Indian English.

As all the variations of English Indian English also has its characteristic features in terms of grammar and here are some of the examples of how Indians use English grammar in different settings to fit better to their needs.

One of the common grammatical peculiarities of Indian English is the way how people make the sentence interrogative:

"Have you no heart, Black Bear? My children are starving. Give me a small piece of meat for them," begged the badger.

(Zitkala-Sa 1901:28)

The above mentioned interrogative construction is out of common use in British English. To make the sentence interrogative in British English instead, the following two constructions should be used: Don't you have a heart? or Do you have no heart? 
Another type of irregularity is observed in the following example where in interrogative sentences the auxiliary is not fronted.

\section{What you would like to eat? and Where you are going?}

(Kachru 1983:126)

A very distinctive characteristic feature typical of Indian English speech is the speed of pronunciation and presumably the focus on speech rather than on its fluency. As a result the word order of the sentence is not only violated but the sentence also acquires additional emotive coloring. It should also be mentioned that generally the Indians prefer to write the way they speak.

According to general syntax rules nouns are preceded by adjectives and they function as attributes in the sentence (adjective + noun). However, it is very common to use the reverse construction (noun+ adjective) in Indian English.

\section{Iktomi dresses like a real Dakota brave.}

(Zitkala Sa 1901:43).

In BE the grammatically correct version of the above utterance would be Iktomi dresses like a real brave Dakota.

It is very typical of Indians to omit articles when they are speaking. Though it may not disturb the interlocutors in oral speech, it is unfavorable to come across such errors in written texts.

Running back to dead fire, they pawed out the ducks with such rude haste that cloud of ashes rose like gray smoke over them.

(ZitkalaSa 1901:52)

In the first part of the sentence the definite article is missing while in the second part the indefinite article is omitted. 
Peter Trudgill and Jean Hannah (1994:129-130) have observed that Indians pluralize many English mass nouns and end up with words such as litters, furnitures, and woods. The opposite technique, i.e. using the singular instead of a plural, is also widely applied.

In BE the predicate usually comes after the subject of the sentence, and thereby we have subject + predicate form. In Indian English the predicate + subject construction is widely used in affirmative sentences.

The differences between BE and IE grammar lead to the claim that Indian English is a variety of English which has certain grammatical peculiarities typical of itself. Many Indians claim that it is very similar to British English, but this observation is mainly reliant on a surface level examination of lexical similarities. One should bear in mind that not all linguistic peculiarities presented above are used by every Indian English speaker and that a great number of regional and educational differentiations exist.

\section{Conclusion}

Dwelling upon the study of Indian English from the grammatical point of view we have come to the conclusion that Indian English and British English are treated as two different autonomous systems; each system has its own rules of grammar. We have found several examples of Indianisms in grammar i.e. how Indians have adapted the language matching it to the way they use language and producing new ways to experience English in other grammatical settings. Grammatical differences vary greatly from interrogative constructions to pluralization of nouns, from word order to article omissions. In general, language evolves and becomes colloquial in local references; hence this process might be one of the reasons why Indian English grammar usage is found to be unusual.

\section{References:}

1. Kachru, B. (1986) The Alchemy of English: The spread, functions and models of non-native Englishes. New York: Pergamon Press Inc.

2. Kachru, B. (1983) The Indianization of English. Oxford: OUP. 
3. Trudgill, P. and Hannah, J. (1994) International English: A Guide to the Varieties of Standard English. London: Edward Arnold.

4. Whitworth, G.C. (1983) An Anglo-Indian Dictionary: a glossary of Indian terms used in English. Edinburgh: Edinburgh University Press.

5. Zitkala-Sa (1901) Old Indian Tales. Boston, London: Ginn and Company.

\section{Sources of Data:}

1. Linguistic Peculiarities of Indian English. Avaliable at: <https://www. emarketer.com/Article/Indias-Internet-Led-by-Local-Languages-NotEnglish/1016151>; $<$ http://shodhganga.inflibnet.ac.in/bitstream/10603/139619/10/10_chapter_4. pdf $>$ [Accessed February 2019].

\section{Zanlquilquis uiquteptêh ptepulquiaulquis

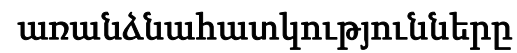

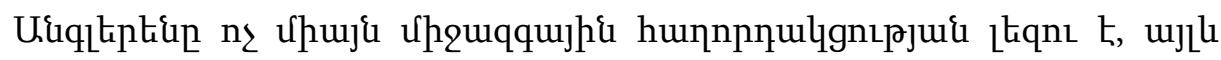

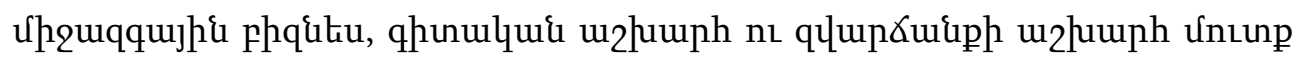

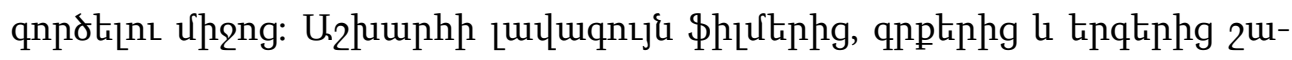

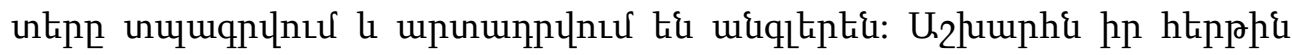

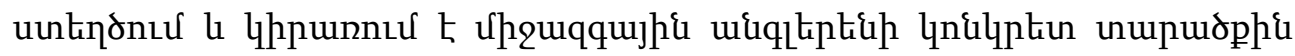

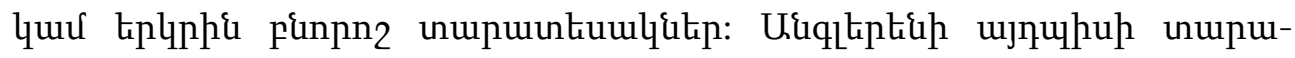

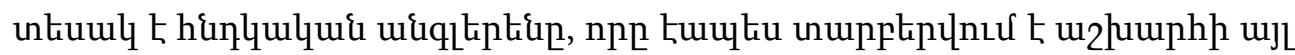

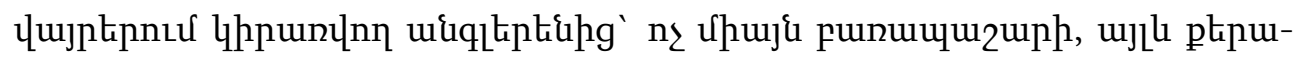

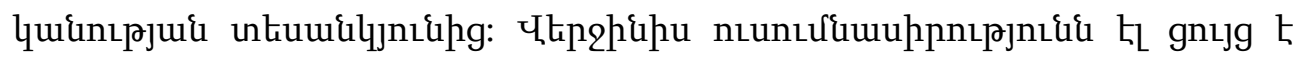

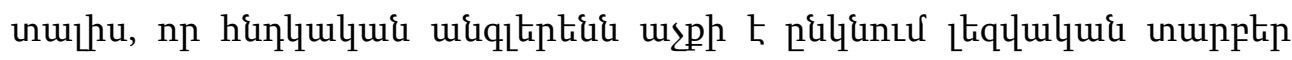

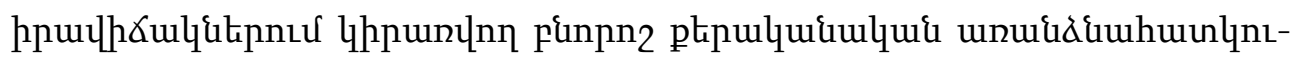
pjnikilinnu:

Received by Editorial Board 01.09.2019

Recommended for publication by Reviewers 22.10.2019

Accepted for Print 01.11.2019 